\title{
Using HyperCard to teach person perception and attribution concepts
}

\author{
LINDA C. PETTY \\ Hampton University, Hampton, Virginia \\ and \\ ELLEN F. ROSEN \\ College of William and Mary, Williamsburg, Virginia
}

\begin{abstract}
HyperCard stacks were used to present and illustrate concepts in person perception and attribution theory. Active participation of learners was maintained through the use of interactive tutorials and simulations requiring frequent learner input. Scanned photographs, cartoons, animations, and diagrams were used to increase learner interest. Two groups of college students were tested after interaction with either the HyperCard stacks or textual materials that presented these concepts to discover the relative effectiveness of the stacks. The HyperCard group scored significantly better on an information test after a 2-h exposure to the material. The same group expressed enthusiasm, enjoyed the study experience, and voiced a desire to have more computerassisted learning experiences, while the other group found the interaction with textual materials boring and did not look forward to a similar experience in the future.
\end{abstract}

The authors have used PCPilot and BASIC for many computer-assisted-instruction (CAI) applications in courses in experimental, motivation, perception, and social psychology. Last year, the first author used Macintosh Plus computers to teach perception. Because the microcomputers did not arrive until the semester had already begun, she used developed software such as the Rice and Drexel experimental laboratories (Chute, 1986; Lane \& Ashby, 1987). After using the Apple Macintosh for one semester, she was convinced that it was the best machine for students, and she began to develop CAI applications in HyperCard. One reason that the Mac was used in our perception course was the availability of software in the area of object perception. However, we also have a unit on person perception and attribution theory in our course, for which there was no software. We therefore chose to develop HyperCard stacks for the study of these subjects. The availability of good, inexpensive scanners such as ThunderScan allows the use of black and white photographs in HyperCard to illustrate such concepts.

Two stacks were produced: PERSON PERCEPTION and ATTRIBUTION THEORY. The first stack is an interactive tutorial that begins by asking students to look at three photographs of people and to type in the first three qualities that come to mind about each stimulus person. The students receive feedback about the frequency of choice

This project was supported in part by a grant from the Minority Science Improvement Program to the Psychology Department at Hampton University. Copies of the HyperCard stacks may be obtained by writing Linda C. Petty, Director, Center for Teaching Excellence, Hampton University, Hampton, VA 23668. among their peers (based on field testing at Hampton University) regarding the qualities that they have noticed for each of the three stimulus people. The first is a young woman, the second a young man, and the last a jazz musician playing a clarinet. An interactive tutorial describing the relationship between object and person perception is presented, with frequent input required from the learner. Likenesses and differences are emphasized, and assumptions that are made about human subjects are explored. Role expectations and "intent-act-effect" sequences are explained and illustrated with the use of text, cartoons, photographs, and diagrams. The student must demonstrate an understanding of the material before proceeding to the next section of the stack.

The nature and development of the categories that structure our perception of other people are then presented in the same format. The student then meets a hypothetical stranger through a simulation that involves photographs and conversation on various topics. The learner forms a first impression through the choice of person perception categories and assignment of ratings in each category. A score is calculated for the first impression to illustrate how these categories are aggregated to form an overall impression. In this way, the simulation makes the unconscious process of impression formation conscious for the student. The stack concludes with a tutorial on stability in object and person perception that includes visual and association constancies as examples.

The attribution stack begins with a description of Heider's (1958) theory of attribution. His basic assumptions are explained and illustrated. Brunswik's (1934) probabilistic functionalism is then discussed, and examples are given. The predisposition of human beings to per- 
ceive patterns is illustrated through visual and auditory examples. The student experiences his or her own bias through interaction with graphical stimuli. The implications of Rotter's (1966) work with locus of control and deCharmes's (1968) ideas about the effect of early environment interaction on causality theory are explained through the use of a tutorial format.

This stack concludes with an explanation of Heider's formulation: EFFECT $=f$ (environmental factors + personal factors). Simulated examples are used to illustrate this function. The learner is asked to solve attribution problems in which the values of the relevant factors are given. Our bias toward seeing internal factors as more important in determining the behavior of others, as opposed to external factors in determining our own behavior, is the last concept presented.

\section{METHOD}

To discover the effectiveness of these stacks in teaching the concepts of person perception and attribution theory, the authors recruited 60 undergraduates at Hampton University to serve as subjects and randomly divided them into two groups of 30. One group was asked to read and study textual materials that covered the information that was presented in the two stacks. The other group was asked to interact with the stacks in the Teaching, Learning Technology Center's student microcomputer laboratory.

About $2 \mathrm{~h}$ were required for the subjects to go through the stacks, so the text group was asked to spend no more than $2 \mathrm{~h}$ studying the material. Both groups then took a test that included multiple-choice items on all topics presented in these materials. Their attitudes were assessed with a 5-item Likert-type scale questionnaire. Four items assessed how they viewed the experience, and the fifth assessed how much the materials contributed to their test scores.

\section{RESULTS}

A significant difference in retention of person perception and attribution concepts was found between the HyperCard and textual groups $[t(58)=10.38$, $p<.0001]$. The mean for the HyperCard group was 78.3, compared to 58.3 for the control group. All attitude measures were extremely positive for the HyperCard group ( $M=24.5$ ), whereas the textual group expressed neutral or negative reactions to the reading materials $(M=10.6)[t(58)=16.3, p<.0001]$. There was no overlap between the groups' reports; none of the HyperCard subjects used a rating of less than 6 ("very much"), and none of the textual group subjects indicated anything higher than a 4 ("slight"). Members of the HyperCard group were unanimous in their desire to work further with computer-assisted learning materials. Both groups indicated that the nature of the learning experience influenced their ability to retain the information contained in the materials.

\section{DISCUSSION}

Results of the testing of these two HyperCard stacks indicate a clear superiority of the computer-based learning experience over the textual experience. The HyperCard stack was better in imparting basic concepts in person perception and attribution theory to undergraduates. Those who used the stacks indicated a strong preference for similar learning opportunities in the future. This group also exhibited extremely positive attitudes toward the interaction and attributed their high retention scores to the enjoyment they experienced as they interacted with the stacks.

\section{REFERENCES}

Brunswik, E. (1934). Wahrnemung und Gegenstandweit. Leipzig and Vienna: Deuticke.

Chute, D. L. (1986). MacLaboratory for psychology: General experimental psychology with Apple's Macintosh. Behavior Research Methods, Instruments, \& Computers, 18, 205-209.

DECharmes, R. C. (1968). Personal causation: The internal affective determinants of behavior. New York: Academic Press.

HEIDER, F. (1958). The psychology of interpersonal relations. New York: Wiley.

Lane, D. M. \& Ashby, B. (1987). PsychLib: A library of machine language routines for controlling psychology experiments on the Apple Macintosh computer. Behavior Research Methods, Instruments, \& Computers, 19, 246-248.

RoTTER, J. B. (1966). Generalized expectancies for internal versus external control of reinforcements. Psychological Monographs, 80, 1-28. 